\title{
Combined Carbon Dioxide Inhibition and Oxygen Limitation of the Growth of Pseudomonas fragi 72 in Batch and Continuous Culture
}

\author{
By GÖRAN MOLIN \\ Swedish Meat Research Institute, P.O. Box 504, S-244 00 Kävlinge, Sweden
}

(Received 15 February 1983)

\begin{abstract}
The effect of $\mathrm{CO}_{2}$ inhibition and $\mathrm{O}_{2}$ limitation on the growth of Pseudomonas fragi strain 72 was studied in carbon and/or energy limited continuous culture using citric acid as the growth substrate. The influence of different $\mathrm{CO}_{2}$ concentrations on the maximal growth capacity, estimated as the dilution rate at which the culture density begins to fall $\left(D_{\mathrm{b}}\right)$ or the dilution rate at which biomass output rate is maximal $\left(D_{\mathrm{m}}\right)$, was demonstrated together with the differences in influence of $\mathrm{CO}_{2}$ inhibition and $\mathrm{O}_{2}$ limitation, on the steady-state characteristics of the culture. The combined effect of $\mathrm{CO}_{2}$ inhibition and $\mathrm{O}_{2}$ limitation was measured. Comparative studies made in batch cultures suggested that continuous culture was more sensitive to change than the batch culture.

The maximum specific growth rate of the organism decreased when the $\mathrm{CO}_{2}$ concentration was increased. However, the results from the continuous cultures revealed a plateau in the curve of $D_{\mathrm{b}}$ versus $\mathrm{CO}_{2}$ concentration (between $3.5 \%$ and $12 \% \mathrm{CO}_{2}$ ). This plateau could not be seen from the $\mu_{\max }$ determinations (batch).

Unlike $\mathrm{O}_{2}$ limitation the $\mathrm{CO}_{2}$ inhibition did not disturb the regularity of the curves of the steady-state characteristics. Two levels of $\mathrm{O}_{2}$ limitation were indicated from the curve of biomass versus dilution rate, a minor one, slightly reducing the biomass concentration of the culture and a major one, significantly reducing the biomass. An $\mathrm{O}_{2}$ concentration of $5 \%$ of the incoming gas (dissolved oxygen tension in the culture: $3-5 \%$ ) had no effect on the steady-state characteristics of the culture, while $0.4 \% \mathrm{O}_{2}$ significantly affected the curve of biomass versus dilution rate (dissolved oxygen tension $0-0.4 \%$ ).

The combined effect of oxygen limitation and $12 \% \mathrm{CO}_{2}$, further altered the steady-state characteristics and the biomass curve started to decrease at very low dilution rates. Thus, the two inhibitory agents co-operated and their joint growth restricting effect was considerably stronger than the strongest agent alone. The question whether the restricting effect of the two together should be regarded as 'synergistic' or 'additive', is still open to discussion even though some evidence was obtained which suggested the former.
\end{abstract}

\section{INTRODUCTION}

The critical role of $\mathrm{O}_{2}$ as a regulator molecule for aerobic metabolism is well established. The effect of $\mathrm{O}_{2}$ limitation of Pseudomonas spp. influences the growth rate at $\mathrm{O}_{2}$ concentrations in the range 0.5 to $4.5 \%(\mathrm{v} / \mathrm{v})$ of the gas phase (Clark \& Burki, 1972; Wells, 1974; Mitchell \& Dawes, 1982). The exact concentration is dependent on factors such as $\mathrm{O}_{2}$ solubility of the substrate, oxygen consumption rate and mixing. A more accurate way to state the actual level of $\mathrm{O}_{2}$ available to the organism is to give a value of the dissolved oxygen tension (DOT). However, the $\mathrm{O}_{2}$ limitation of Pseudomonas usually starts at such low DOT values that they are difficult to measure.

$\mathrm{CO}_{2}$ is suspected of being as important a regulator molecule of metabolism as $\mathrm{O}_{2}$ but understanding of the mechanisms is considerably more vague (Jones \& Greenfield, 1982). On the other hand, the growth inhibitory effects of high concentrations of $\mathrm{CO}_{2}$ have become evident 
through reports stretching from Pasteur \& Joubert (1877) to Enfors \& Molin (1981). Furthermore, the inhibitory effect on Pseudomonas spp. in particular, has been frequently studied, e.g. Clark \& Lentz (1969), Gill \& Tan (1980) and Enfors \& Molin (1980). However, many of the results conflict with respect to the pattern of the curve of $\mathrm{CO}_{2}$ concentration versus growth rate. Explanations could be offered in terms of the effect of growth substrate or the inherent genetic differences between different species or strains. Some of the discrepancies may also be blamed on the application, in some cases, of fairly crude systems to measure the growth rate. All the experiments were carried out in batch cultures.

Knowledge of the combined effects of $\mathrm{CO}_{2}$ inhibition and $\mathrm{O}_{2}$ limitation is scarce. The phenomenon has been tentatively studied in batch cultures by Wells (1974) and Enfors \& Molin (1980). Wells indicated that the two growth restricting agents were 'antagonistic' (no extra inhibitory effect) but in the latter study it was indicated that they were 'additive' or even 'synergistic'. The effect of high $\mathrm{O}_{2}$ concentrations together with the effect of $\mathrm{CO}_{2}$ has been studied in continuous culture on the alga Chlorella (Pirt \& Pirt, 1980) but no similar reports on $\mathrm{O}_{2}$ limitation have been found in the literature.

The present paper reports the growth inhibitory effect of $\mathrm{CO}_{2}$ in a steady-state culture and the combined effect of $\mathrm{CO}_{2}$ inhibition and $\mathrm{O}_{2}$ limitation in the same test system. Comparisons are made with batch cultures.

\section{METHODS}

Organism. Pseudomonas fragi 72 was originally isolated from cold stored beef and classified by Molin \& Ternström (1982). Stock cultures were stored freeze-dried in skimmed-milk at $4{ }^{\circ} \mathrm{C}$.

Culture equipment. The culture vessel was a fermenter with a working volume of 1.01 (Chemoferm AB, Hägersten, Sweden). The fermenter was continuously fed with medium by a membrane pump (Precision dosage pump Fe 211, Braun, Melsungen, F.R.G.) and continuous outflow was achieved via an overflow outlet and a tube pump (MHRE Mk 3 flow inducer, Watson-Marlow, Falmouth, U.K.). The stirrer speed was constant at 1200 r.p.m. (impeller: 4 wings, diameter $45 \mathrm{~mm}$ ). The $\mathrm{pH}$ was kept constant $(\mathrm{pH}=6.0$ ) by titration with $0.6 \mathrm{M}-$ $\mathrm{HCl}$ or $1 \mathrm{M}-\mathrm{NaOH}$ (pH M 62 + TTT 60, Radiometer, Copenhagen, Denmark). The temperature was controlled via a heating bath which circulated water around an outer shell of the fermenter.

Gas supply. The chosen gas compositions were supplied to the culture at the following flow rates $\left(1 \mathrm{~h}^{-1}\right):$ air, 71 ; $50 \% \mathrm{CO}_{2}+$ air, 80;16\% $\mathrm{CO}_{2}+$ air, $81 ; 12 \% \mathrm{CO}_{2}+$ air, $78 ; 6 \% \mathrm{CO}_{2}+$ air, $74 ; 3.5 \% \mathrm{CO}_{2}+$ air, $73 ; 75 \% \mathrm{~N}_{2}+$ air $\left(5 \% \mathrm{O}_{2}\right), 95 ; 98 \% \mathrm{~N}_{2}+\operatorname{air}\left(0.4 \% \mathrm{O}_{2}\right), 72 ; 11 \% \mathrm{CO}_{2}+0.4 \% \mathrm{O}_{2}+\mathrm{N}_{2}, 71$. The air was mixed with $\mathrm{CO}_{2}$ (purity: 99.998\%; Alfax AB, Malmö, Sweden) or nitrogen (99.999\%; Alfax AB) aided by flow meters (F-150-A, Porter Instrument $\mathrm{Co}$. Ltd, Hadfield, U.K.). The mixture of $11 \% \mathrm{CO}_{2}+0.4 \% \mathrm{O}_{2}+\mathrm{N}_{2}$ was purchased directly from the manufacturer (Alfax AB).

The $\mathrm{CO}_{2}$ and $\mathrm{O}_{2}$ contents of the outgoing gas from the fermenter were monitored continuously by a Binos 1 infrared gas analyser (Leybold-Heraeus, Köln, F.R.G.) and a Servomex oxygen analyser (paramagnetic; OA 540, Taylor Instrument Analytics Ltd, Crowborough, Sussex, U.K.), respectively. The DOT was measured by an oxygen electrode (Radiometer) connected to a TOX 40 oxygen transmitter (Radiometer) and is given as percentage of the value obtained under a theoretical atmosphere of $100 \% \mathrm{O}_{2}$ (the measurement was performed with an electrode calibrated in air).

Medium. The continuous culture medium had the following composition $\left(\mathrm{g}^{-1}\right)$ : citric acid (1-hydrate; 244, Merck), $1.0 ; \mathrm{MgSO}_{4}, 0 \cdot 5 ; \mathrm{Na}_{2} \mathrm{HPO}_{4} .2 \mathrm{H}_{2} \mathrm{O}, 0 \cdot 40 ; \mathrm{KH}_{2} \mathrm{PO}_{4}, 0 \cdot 37 ;\left(\mathrm{NH}_{4}\right)_{2} \mathrm{SO}_{4}, 0 \cdot 25 ; \mathrm{CaCl}_{2}, 0 \cdot 10 ; \mathrm{MnSO}_{4} . \mathrm{H}_{2} \mathrm{O}$, $0.05 ; \mathrm{FeSO}_{4} .7 \mathrm{H}_{2} \mathrm{O}, 0.01 ; \mathrm{CuSO}_{4} .5 \mathrm{H}_{2} \mathrm{O}, 0.005 ; \mathrm{ZnSO}_{4} .7 \mathrm{H}_{2} \mathrm{O}, 0.005 ; 0.10 \mathrm{ml}$ Silicone antifoaming agent (BDH) $1^{-1}, \mathrm{pH}$ was adjusted using $\mathrm{HCl}$ or $\mathrm{NaOH}$ to 5.0 before autoclaving (in 201 bottles at $121^{\circ} \mathrm{C}$ for $60 \mathrm{~min}$ ) and to 6.0 afterwards. The same medium was used for the batch cultures except that it contained $3.0 \mathrm{~g}$ citric acid $1^{-1}$.

Inoculation. The freeze-dried cultures were recovered in Nutrient broth (Oxoid; shaken bottles) at $25^{\circ} \mathrm{C}$ for $8 \mathrm{~h}$ and then transferred to a bottle with the medium described above but with $5.0 \mathrm{~g}$ citric acid $1^{-1}$. After $16 \mathrm{~h}\left(25^{\circ} \mathrm{C}\right.$; shaken) the fermenter was inoculated. The inoculum was $8 \%$ of the fermenter volume.

Growth experiments. The inoculated fermenter, sparged with a chosen gas, was run as a batch culture for 7-9 h after which the continuous culture was started. The continuous culture was run on citric acid as a carbon source and/or energy limited chemostat for a total time of 7-10 d.

The continuous culture was started at the lowest dilution rate (about $0.1 \mathrm{~h}^{-1}$ ), the dilutation rate then being successively increased until wash-out was almost reached. Each dilution rate was maintained for $24 \mathrm{~h}$ before any measurements were made $\left(40 \mathrm{~h}\right.$ for $D=0.1$ and $64 \mathrm{~h}$ for $D<0 \cdot 1$ ). All cultures were performed at $25^{\circ} \mathrm{C}$ and $\mathrm{pH} 6 \cdot 0$. 


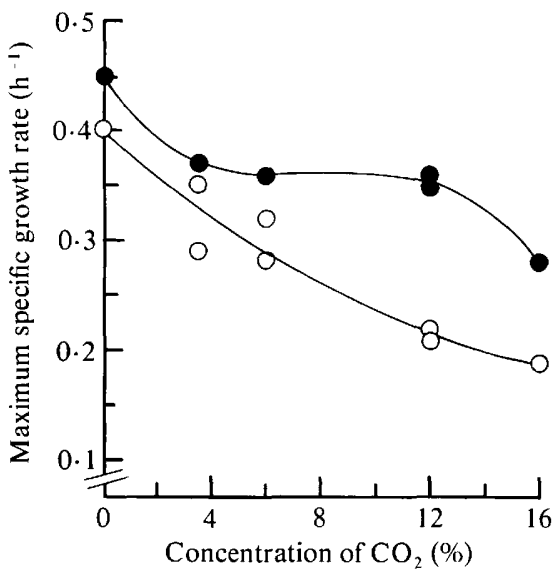

Fig. 1. Maximal growth capacity of Pseudomonas fragi 72 at different $\mathrm{CO}_{2}$ concentrations of the outgoing gas phase: $\bigcirc, \mu_{\max }$ estimated from batch cultures; - dilution rate of biomass decrease estimated from carbon and energy limited continuous cultures $\left(D_{\mathrm{b}}\right.$, the dilution rate where the curve of biomass versus dilution rate had decreased by $0.03 A_{620}$ units from its maximum value).

Analytical methods. When the culture was in steady-state at a specific dilution rate, the following measurements were performed: absorbance at $A_{620}$ (Turner spectrophotometer, 330 ; the same $1 \mathrm{~cm}$ cuvette was used for all measurements), dry weight, viable count [Tryptone glucose extract agar, (Difco) for $3 \mathrm{~d}$ at $25^{\circ} \mathrm{C}$ ], and citric acid concentration (enzymically; Lebensmittelanalytik, Boehringer-Mannheim).

Both the viable count and the dry weights roughly followed the $A_{620}$ values. However, the latter was generally more reproducible and in the present study the biomass is reported as absorbance.

Determination of maximal growth capacity. The maximum specific growth rate was calculated from the batch culture (Pirt, 1975). In $\mathrm{CO}_{2}$ the growth curves of the batch cultures ( $\log A_{620}$ versus time) sometimes showed two exponential phases. The first was short and steep and the second one was considerably longer and somewhat flatter. The latter was used to calculate $\mu_{\max }$.

In contrast, under reduced input of $\mathrm{O}_{2}, \mu_{\max }$ was calculated from the first part of the growth curve. The curve then became non-exponential.

A value of the maximal growth capacity of the continuous culture was obtained by estimating, from the curve of the biomass versus dilution rate, the dilution rate where the biomass had decreased $0.03 A_{620}$ units from its maximum value (dilution rate of biomass decrease, $D_{\mathrm{b}}$ ) and by estimating the dilution rate of the maximum output rate (dilution rate of maximum output rate, $D_{\mathrm{m}}$ ),

\section{RESULTS}

The effect of different $\mathrm{CO}_{2}$ concentrations on the maximal growth capacity estimated as $\mu_{\max }$ and $D_{\mathrm{b}}$ is given in Fig. 1. A corresponding curve of $D_{\mathrm{m}}$ versus $\mathrm{CO}_{2}$ concentration coincides with that of $D_{\mathrm{b}}$. There was a marked difference in shape between the $\mu_{\max }$ curve obtained from batch cultures and the $D_{\mathrm{b}}$ curve obtained from continuous cultures. The $\mathrm{CO}_{2}$ concentration of the culture grown under an air atmosphere was $0.2 \%$ when the output rate of the culture was at its maximum. The maximum specific growth rate at $50 \% \mathrm{CO}_{2}$ was $0.10 \mathrm{~h}^{-1}$.

The steady-state characteristics of the culture under air and a mixture of $12 \% \mathrm{CO}_{2}$ plus air are shown in Fig. 2(a,b). The biomass at carbon source limited steady-state was slightly lower in $12 \% \mathrm{CO}_{2}$ than in pure air. The yield coefficient was decreased from about 0.44 to $0.39\left(A_{620}\right.$ units per $\mathrm{g}$ citric acid). The yield was about $0.44,0.40$ and 0.37 for $3.5 \%, 6 \%$ and $16 \% \mathrm{CO}_{2}$, respectively.

The dry weights at carbon source limited steady-state were $0 \cdot 2-0 \cdot 3 \mathrm{~g} \mathrm{l}^{-1}$ for all the tested $\mathrm{CO}_{2}$ concentrations and the viable count was about $3 \times 10^{8}$ c.f.u. $\mathrm{ml}^{-1}$.

The DOT was on no occasion lower than $18 \% \mathrm{O}_{2}$ in any of the cultures of Fig. 1. The maximum specific growth rate as well as $D_{\mathrm{b}}$ was unaffected by a decreased $\mathrm{O}_{2}$ concentration of 

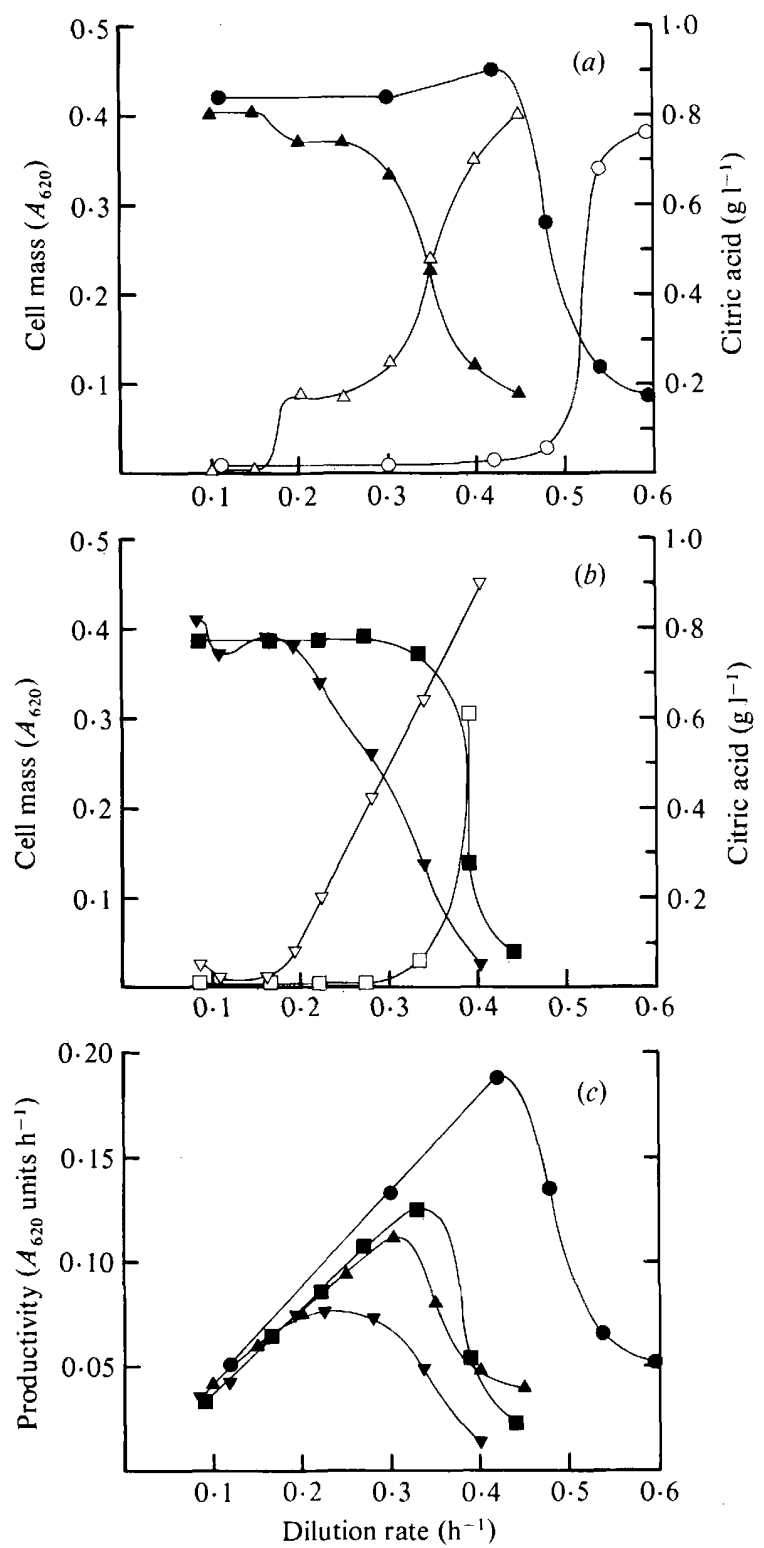

Fig. 2. Steady-state characteristics of Pseudomonas fragi 72 in continuous culture. (a) Biomass $(\boldsymbol{O})$ and substrate concentration $(O)$ in air; biomass $(\Delta)$ and substrate concentration $(\triangle)$ in $0.4 \% \mathrm{O}_{2}+\mathrm{N}_{2} .(b)$ Biomass $(\boldsymbol{\square})$ and substrate concentration $(\square)$ in $12 \% \mathrm{CO}_{2}+$ air; biomass $(\nabla)$ and substrate concentration $(\nabla)$ in $0.4 \% \mathrm{O}_{2}+12 \% \mathrm{CO}_{2}+\mathrm{N}_{2}$. (c) Biomass output rate/productivity in air $(\bullet), 12 \%$ $\mathrm{CO}_{2}+\operatorname{air}(\boldsymbol{\square}), 0.4 \% \mathrm{O}_{2}+\mathrm{N}_{2}(\boldsymbol{\Delta})$ and $0.4 \% \mathrm{O}_{2}+12 \% \mathrm{CO}_{2}+\mathrm{N}_{2}(\boldsymbol{v})$.

the incoming gas phase down to $5 \%$ which corresponded to a DOT of 3-5\%. However, at an $\mathrm{O}_{2}$ concentration of $0.4 \%$ of the gas phase (DOT, $0-0.4 \% \mathrm{O}_{2}$ ), the culture was severely limited (Fig. $2 a$ ). The maximum specific growth rate of the batch was $0.24 \mathrm{~h}^{-1}$ whereas the biomass curve of the continuous culture dropped in two stages, indicating a step-by-step $\mathrm{O}_{2}$ limitation at increasing dilution rates, i.e. a primary limitation at $0 \cdot 19 \mathrm{~h}^{-1}$ and a secondary limitation at $0 \cdot 30 \mathrm{~h}^{-1}$. The initial decrease in biomass was also slightly reflected in the curve of the output rate (Fig. $2 c$ ). However, the output-rate curve of the $\mathrm{O}_{2}$ limited culture had a similar appearance to that of the pure air. This is in spite of the significant discrepancies in shape between the curves 
Table 1. Maximal growth capacity of Pseudomonas fragi 72 in batch and continuous culture

Maximal growth capacity is measured as maximum specific growth rate $\left(\mu_{\max }\right)$ in batch cultures, and as the dilution rate of biomass decrease $\left(D_{\mathrm{b}}\right)$ and the dilution rate of maximum output rate $\left(D_{\mathrm{m}}\right)$ in continuous cultures.

\begin{tabular}{|c|c|c|c|c|c|c|}
\hline \multirow[b]{2}{*}{ Gas atmosphere } & \multicolumn{2}{|c|}{ Batch culture } & \multicolumn{4}{|c|}{ Continuous culture* } \\
\hline & $\underset{\left(\mathrm{h}^{-1}\right)}{\mu_{\max }}$ & $\begin{array}{l}\text { RI }+ \\
(\%)\end{array}$ & $\begin{array}{c}D_{\mathrm{b}} \ddagger \\
\left(\mathrm{h}^{-1}\right)\end{array}$ & $\begin{array}{l}\text { RI } \dagger \\
(\%)\end{array}$ & $\begin{array}{c}D_{\mathrm{m}} \S \\
\left(\mathbf{h}^{-1}\right)\end{array}$ & $\begin{array}{l}\text { RI } \\
(\%)\end{array}$ \\
\hline Air & 0.40 & 0 & $0 \cdot 45$ & 0 & 0.42 & 0 \\
\hline $0.4 \% \mathrm{O}_{2}+\mathrm{N}_{2}$ & $0 \cdot 24$ & 40 & $0 \cdot 30(0 \cdot 19)$ & $33(58)$ & $0 \cdot 31$ & 26 \\
\hline $12 \% \mathrm{CO}_{2}+$ air & $0 \cdot 22$ & 45 & $0 \cdot 35$ & 22 & 0.33 & 21 \\
\hline $11 \% \mathrm{CO}_{2}+0.4 \% \mathrm{O}_{2}+\mathrm{N}_{2}$ & 0.24 & 40 & $0.21(<0.11)$ & $53(>76)$ & 0.23 & 45 \\
\hline
\end{tabular}

* Values within parentheses are based on the initial fall of the $A_{620}$ curve (Fig. 2).

$\dagger$ Relative inhibition, RI $=100\left(r_{\mathrm{c}}-r\right) r_{\mathrm{c}}{ }^{-1}$ where $r_{\mathrm{c}}$ and $r$ are the values of the control culture (air) and the restricted culture, respectively.

$\ddagger$ The dilution rate where the curve of biomass versus dilution rate has decreased by $0.03 A_{620}$ units from its maximum value.

$\S$ The dilution rate where the culture has its maximum output rate.

of biomass versus dilution rate. The yield at both phases $\left(A_{620}\right.$ constant) was about $0.4\left(A_{620}\right.$ units per $\mathrm{g}$ citric acid), which is the same as in air.

The steady-state characteristics of a culture that was simultaneously $\mathrm{O}_{2}$ limited $\left(0 \cdot 4 \% \mathrm{O}_{2}+\right.$ $\mathrm{N}_{2}$ ) and $\mathrm{CO}_{2}$ inhibited ( $12 \% \mathrm{CO}_{2}+$ air), are shown in Fig. $2(b)$. The $A_{620}$ curve appears somewhat irregular at low dilution rates with a fairly flat slope down to higher dilution rates. The peak of the productivity curve maximum was rounded (Fig. $2 c$ ).

The combined effect of $\mathrm{CO}_{2}$ and low $\mathrm{O}_{2}$ content is compared in Table 1 with each inhibitory factor alone. According to the batch studies of the $\mu_{\max }$ values, the relative inhibitory effect of $\mathrm{O}_{2}$ limitation and $\mathrm{CO}_{2}$ are about equal. Furthermore, the combined effect is about the same as that for each factor on its own. However, the situation drastically altered when the effects were evaluated from the drop in biomass of the steady-state cultures $\left(D_{\mathrm{b}}\right)$. The growth preventing effect of $\mathrm{O}_{2}$ limitation was larger than that of $\mathrm{CO}_{2}$ inhibition and the combined effect was considerably larger than the $\mathrm{O}_{2}$ limitation by itself (Table 1 ).

It can be seen that the sum of the restriction due to $\mathrm{CO}_{2}(20 \%)$ and of $\mathrm{O}_{2}$ limitation $(33 \%)$ should be $48 \%$ if the values of the relative reduction are compared. Addition of reductions is done according to the formula:

sum of reductions $=B+C-B C 100^{-1}$

where $B$ is the reduction in $\mathrm{CO}_{2}$ and $C$ the reduction at $\mathrm{O}_{2}$ limitation. In contrast, the experimentally-found effect of both $\mathrm{CO}_{2}$ inhibition and $\mathrm{O}_{2}$ limitation together was $53 \%$ (Table 1), i.e. $5 \%$ larger than expected from pure addition.

If the calculation is made using the values of primary $\mathrm{O}_{2}$ limitation (values within parentheses in Table 1) the difference between theoretical and experimental values is $>9 \%$. However, when the calculation was made from the $D_{\mathrm{m}}$ values, the difference was only $3 \%$.

\section{DISCUSSION}

The maximal growth capacity of the culture was given as $\mu_{\max }$ in the batch cultures. However, it was difficult to calculate any reliable $\mu_{\max }$ values from the continuous cultures.

The method of 'wash out' (Pirt, 1975) was tried and found to be unreliable. Maximum specific growth rates obtained in this way were not constant but highly dependent upon the dilution rate that preceded the wash-out experiment; the dilution rate of the wash-out; the age of the continuous culture. Another way to determine $\mu_{\max }$ had been to use a reciprocal plot of growth rate (dilution rate) versus substrate concentration (Pirt, 1975). However, no reliable values could be calculated from the present data as the plot was not linear. 
These difficulties may have been caused by attached growth in the fermenter, a phenomenon which had earlier been demonstrated as being a problem in continuous cultures of Pseudomonas (Molin, 1981). Attached growth may also underlie the finding that steady-states in the present study were obtained at dilution rates far above the $\mu_{\max }$ calculated from the batch cultures.

In the absence of reliable $\mu_{\max }$ values the estimated $D_{\mathrm{b}}$ and $D_{\mathrm{m}}$ values make it possible to compare the maximal growth capacity of the continuous culture under different conditions. However, the way $D_{\mathrm{b}}$ or $D_{\mathrm{m}}$ relate to the true $\mu_{\max }$ of a continuous culture and whether the $\mu_{\max }$ value of a batch and its corresponding continuous culture really are equal, cannot be answered by the present study.

The response of the growth rate to different $\mathrm{CO}_{2}$ concentrations is shown in Fig. 1. The "batch curve' had a similar shape to that reported earlier for $P$. fragi ATCC $4973\left(8-90 \% \mathrm{CO}_{2}\right.$; Enfors \& Molin, 1980). However, the $\mathrm{CO}_{2}$ effect on $D_{\mathrm{b}}$ was different in the continuous cultures and a plateau in the decreasing curve was revealed at 3.5-12\% $\mathrm{CO}_{2}$ (Fig. 1). The principal difference between the two test systems may offer an explanation for the apparent discrepancy in $\mathrm{CO}_{2}$ response. Thus, in the continuous cultures the organism (1) has been accustomed to the $\mathrm{CO}_{2}$ atmosphere for several days before it had to make use of its maximal growth capacity, and (2) no biological material from the inoculum was left in the fermenter when the maximal growth capacity was determined. Therefore the continuous culture is probably a more accurate testing tool and suggests a truer picture of how growth is influenced by the $\mathrm{CO}_{2}$ concentration.

The DOT in a continuous culture with a constant input of a limited amount of $\mathrm{O}_{2}$ will gradually decrease with dilution rate (growth rate) until not enough $\mathrm{O}_{2}$ is available for full metabolic activity. At this point the biomass will start to decrease and the relationship between growth rate, total biomass and available $\mathrm{O}_{2}$ will control the shape of the biomass curve. According to Pirt (1975) this fall in the curve is initially steep, subsequently becoming flatter until the point where the culture is washed-out at about the same dilution rate as a carbon source limited culture with full access to $\mathrm{O}_{2}$. However, this behaviour was not shown by the $\mathrm{O}_{2}$ limited continuous culture in the present study (Fig. 2a), where the biomass curve had a plateau indicating a step-by-step $\mathrm{O}_{2}$ limitation. This is unexpected in view of what has just been said. It was likewise unexpected that the growth curves of the $\mathrm{O}_{2}$ restricted batch cultures were exponential over a significant length of time from where a $\mu_{\max }$ could be calculated. Both the results found in batch and in continuous culture would suggest that the growth rate of an $\mathrm{O}_{2}$ limited culture is controlled by the availability of $\mathrm{O}_{2}$ in a stepwise pattern, i.e. the growth rate is not changing continuously with changes in DOT.

The combined effect of $\mathrm{CO}_{2}$ inhibition and $\mathrm{O}_{2}$ limitation gave steady-state characteristics that followed curves of new, and in the case of the biomass, irregular patterns without any clear plateaux (Fig. 2b). However, the curves indicate that some change occurred in the cultures at an approximate dilution rate of $0 \cdot 1 \mathrm{~h}^{-1}$. This was, unfortunately, also the starting point of the experiment. Nevertheless, it could suggest that there is a primary $\mathrm{O}_{2}$ limitation around the dilution rate of $0 \cdot 1 \mathrm{~h}^{-1}$.

When the combined effect of $\mathrm{O}_{2}$ limitation and a growth inhibiting factor $\left(\mathrm{CO}_{2}\right)$ is to be studied, it could be argued that the additional inhibitor slows down growth and $\mathrm{O}_{2}$ consumption rate leading to a less strict $\mathrm{O}_{2}$ limitation. In fact, this could be one explanation of the apparently poor inhibition by $\mathrm{CO}_{2}$ and $\mathrm{O}_{2}$ limitation when tested in batch cultures (Table 1). On the other hand, this cannot be the explanation for the results obtained with continuous culture where the $\mathrm{O}_{2}$ restriction started at a considerably lower dilution rate than the $\mathrm{CO}_{2}$ inhibition (Fig. $2 a, b$ ). In the continuous culture $\mathrm{O}_{2}$ restriction and $\mathrm{CO}_{2}$ inhibition are not antagonistic but cooperative, i.e. the two factors together gave a greater reduction in growth than each factor alone (Table 1). However, it cannot be determined whether they are 'additive' or 'synergistic'. There is some evidence suggesting the latter, but the comparison of the two growth restricting agents was only made with a single set of conditions. This is particularly important since it has been argued that discussion about additivity/synergism could not be held on the basis of 'an effect' (in the present study the apparent growth rate at a certain condition) but must be based on 'a quantity' (for example, the amount of inhibitory agent necessary to obtain the value $\mu_{\max } 2^{-1}$ where $\mu_{\max }$ is the growth rate at optimum growth conditions; Voorspuij, 1977). Nevertheless, at the 
concentrations tested, the combined effect of $\mathrm{CO}_{2}$ inhibition and $\mathrm{O}_{2}$ limitation was considerably larger than either agent working alone.

The author is indebted to Ms Eva Andersson and Ms Britt-Marie Wahlqvist for their skilful technical assistance. This study was supported by the Swedish National Board for Technical Development.

\section{REFERENCES}

CLARK, D. S. \& BURKI, T. (1972). Oxygen requirements of strains of Pseudomonas and Achromobacter. Canadian Journal of Microbiology 18, 321-326.

Clark, D. S. \& Lentz, C. P. (1969). The effect of carbon dioxide on the growth of slime producing bacteria on fresh beef. Canadian Institute of Food Technology Journal 2, 72-75.

ENFORS, S.-O. \& Molin, G. (1980). Effect of high concentrations of carbon dioxide on growth rate of Pseudomonas fragi, Bacillus cereus and Streptococcus cremoris. Journal of Applied Bacteriology 48, 409-416.

ENFors, S.-O. \& Molin, G. (1981). The influence of temperature on the growth inhibitory effect of carbon dioxide on Pseudomonas fragi and Bacillus cereus. Canadian Journal of Microbiology 27, 15-19.

GILL, C. O. \& TAN, K. H. (1980). Effect of carbon dioxide on growth of meat spoilage bacteria. Applied and Environmental Microbiology 39, 317-319.

JONES, R. P. \& GREENFIELD (1982). Effect of carbon dioxide on yeast growth and fermentation. Enzyme and Microbial Technology 4, 210-223.

Mitchell, C. G. \& Dawes, E. A. (1982). The role of oxygen in the regulation of glucose metabolism, transport and the tricarboxylic acid cycle in Pseudomonas aeruginosa. Journal of General Microbiology $128,49-59$.
Molin, G. (1981). The impact of dilution rate and attached growth on steady-state characteristics of Pseudomonas putida. European Journal of Applied Microbiology and Biotechnology 13, 102-106.

Molin, G. \& TernströM, A. (1982). Numerical taxonomy of psychrotrophic pseudomonads. Journal of General Microbiology 128, 1249-1264.

PAsteur, L. \& Joubert, L. (1877). Etude sur la maladie charbonneuse. Comptes rendus hebdomadaires des séances de l'Académie des sciences 84, 900906.

PIRT, M. W. \& PIRT, S. J. (1980). The influence of carbon dioxide and oxygen partial pressures on chlorella growth in photosynthetic steady-state cultures. Journal of General Microbiology 119, 321-326.

PIRT, S. J. (1975). Principles of Microbe and Cell Cultivation. Oxford: Blackwell Scientific Publications.

VoorspuIJ, A. J. Z. (1977). Some fundamental reflections on "antimicrobial potency". In Antibiotics and Antibiosis in Agriculture, pp. 284-295. Edited by M. Woodbine. London: Butterworths.

Wells, J. M. (1974). Growth of Erwinia carotovora, E. atroseptica and Pseudomonas fuorescens in low oxygen and high carbon dioxide atmospheres. Phytopathology 64, 1012-1015. 